\title{
Evaluation of Sustainable Tourism Development of the Hotel Industry in Hainan, China by Earth Check
}

\author{
Hongjuan Song1, Zhenxiang Zhang ${ }^{2}$ \\ ${ }^{1}$ The Department of Extension, University of California, San Diego, USA \\ ${ }^{2}$ The School of Tourism Management, Qiongzhou University, Sanya, China \\ Email: shj5126@163.com
}

Received 20 October 2014; revised 22 November 2014; accepted 2 December 2014

Copyright (C) 2014 by authors and OALib.

This work is licensed under the Creative Commons Attribution International License (CC BY). http://creativecommons.org/licenses/by/4.0/

(c) (i) Open Access

\section{Abstract}

The tourism industry has a higher dependence on natural and cultural resources and is more vulnerable to environmental impacts than any other industry. It faces a plethora of issues, risks, and opportunities related to sustainability and environmental change. The hotel industry is one of the most important parts of tourism. Three China Green certified hotels (the Guesthouse International Hotel Sanya, the Leaguen Resort Sanya Bay and the Boao Golden Coast Hot Spring Hotel) are being chosen as samples for our case studies. This paper introduces these three hotels, and then gives the results from the field investigation and the interviews conducted with hotel staff. Based on the data collected, this paper uses Earth Checkas, a sustainable development evaluation tool, to assess these three hotels. Through evaluating our results, we verify whether the China Green Hotel standard meets the international standard requirements of Earth Check. Meanwhile, with this inspection we determine whether Earth Check is suitable for application in the China hotel industry and the whole tourism industry. Through our research of these three hotels, we found that the Earth Check standard can be implemented in the hotel industry in China to help these hotels develop a sustainable hotel.

Keywords

Sustainability, Environmental Management, Hotel Industry, Benchmarking, Earth Check

Subject Areas: Environmental Sciences, General Management

\section{Introduction}

According to the World Travel \& Tourism Council (WTTC) [1], Travel \& Tourism continues to be one of the

How to cite this paper: Song, H.J. and Zhang, Z.X. (2014) Evaluation of Sustainable Tourism Development of the Hotel Industry in Hainan, China by Earth Check. Open Access Library Journal, 1: e854. http://dx.doi.org/10.4236/oalib.1100854 
world's largest industries. The total impact of the industry means that, in 2011, it has contributed 9\% of global GDP or a value of over \$6 trillion US dollars, and accounted for 255 million jobs. Over the next ten years this industry is expected to grow by an average of $4 \%$ annually, taking it to $10 \%$ of the global GDP, or some $\$ 10$ trillion US dollars. By 2022, it is anticipated that it will account for 328 million jobs; this is 1 of every 10 jobs on the planet. But the rapid development of the tourism industry also has negative impacts on the environment. The contradiction between tourism development and the balance of nature is deepening. With the continued expansion of the tourism industry comes the challenge of balancing the economic benefits of tourism development and growth with the need to protect the very things that tourists go to see, which includes clean beaches, authentic communities, landscapes, culture and nature. For tourism to be profitable and beneficial, it must also be sustainable by providing benefits to the tourists and hosts, while at the same time protecting the resources on which it depends. In order to keep tourism healthy, we need to integrate the concepts of sustainable development into the process of tourism. Sustainable tourism has been developing for more than 30 years. In order to distinguish sustainable tourism from non-sustainable tourism, it's important to apply sustainable and Eco-tourism certification to the tourism industry.

Currently, there are thousands of sustainable tourism and Eco-tourism certifications in the world. A certification process provides a strong guarantee and metrics to solve the issues of resource utilization, environmental pollution, labor, and community harmony. These sustainable tourism and Eco-tourism certifications also provide the opportunity of "Green washing". China's rapid economic development has made China the second superpower of the world economy. The tourism industry of China has become the world's third-largest tourism power. However, due to the limited awareness of environmental protection under a rapidly developing economy, some negative impacts are starting to appear. Therefore, we need to find a way to improve the sustainability of the tourism industry in China as well as improve people's awareness of environmental protection. Can sustainable tourism certifications promote and guarantee the tourism industry a sustainable and rapid development? How does the sustainable tourism certification work in regards to the process of assessment and certification? Could the international sustainable tourism certification apply to the China tourism industry? How can the international sustainable tourism certification be applied and promoted in the China hotel industry? The study of sustainable tourism and Eco-tourism certification in China is still in its infancy, and related research is rare. There were no Earth Check cases or thesis papers that could be retrieved. So, in this paper, the authors will explain the answers to the above questions.

\section{Literature Review}

\subsection{Definition of Earth Check}

Earth Check is the leading benchmarking, certification and environmental management program used by the travel and tourism industry. It is also one of the world's largest certifiers of sustainable travel and of tourism operators, with more than 1300 clients in over 70 countries worldwide.

From the Earth check home page [2]:

"For over a decade, Earth Check has been collecting data relating to the operational performance of more than 1300 travel and tourism organizations in over 84 countries. This has enabled Earth Check clients to competitively benchmark the efficiency of their operations against internationally compliant standards of Best Practice. Earth Check recognizes 39 sectors in the travel and tourism industry and helps operators to measure, monitor and manage their environmental, social and economic impacts. This includes the reporting of Greenhouse Gas emissions (GHG) and consumption of natural resources. Earth Check has remained true to its roots in science, research, and innovation. It has matured into a standalone brand that is trusted by market leaders such as InterContinental Hotels Group, Taj Hotels, Sandals, Langham Hospitality Group, Banyan Tree and ACCOR.”

\subsection{Criteria: Earth Check Benchmarking Indicators and Checklists}

Before February, 2010, the Earth Check science system was used by Green Globe. So, we cannot directly use the year before 2010 for Earth Check benchmarking indicators. From the Earth Check web site, the "Case Studies" we downloaded were some of the latest Earth Check Benchmark Reports. By summarizing these Benchmark Reports, we find that they all use the same benchmarking indicators. These eight benchmarking indicators also appeared in Aoife Anne-Marie Houlihan Wiberg's PhD thesis, "An Analysis of the Performance of Certification Schemes in the Hotel Sector In terms Of $\mathrm{CO}_{2}$ Emissions Reduction”. Our group interviewed and corres- 
ponded through email with Ms. Yan Ke, who is the Earth Check China Regional Director. She also sent emails and the Chinese Edition Handbook of the Earth Check Program, which included the same Earth Check benchmarking indicators we use for our evaluations. The annual assessment of the hotels and resorts in the travel and tourism industry were compared against Earth Check's benchmarking indicators and checklists were developed for Earth Check and are listed below in Table 1. Tourism companies have been carefully selected in order to track performance in key areas of environmental and social performance. Their outcomes are presented in the Earth Check Benchmark Report and are used by Earth Check to evaluate whether the operation has reached the standards necessary for certification.

Descriptions for the above table are from the latest case study and the Chinese edition Handbook for Earth Check:

Refer to the Earth Check Sector Benchmarking Indicator (SBI) document for more information. For frequently asked questions (FAQs) about benchmarking or specific help, please log on to "My Earth Check" and visit the Earth Check Benchmarking software.

To meet the requirements stipulated in the Earth Check Company Standard, the benchmarks for all the submitted Earth Check indicators need to be at, or better than, the Baseline level. Baseline and Best Practice performance levels are set with reference to the type of activity (registered sector/s) and appropriate national and international data which takes into account the social, geographical and climatic impacts.

First-time benchmarking operations that fail to meet the minimum requirements (Baseline performance or better) for up to two submitted Earth Check indicators (with a third indicator within 10\% of the Baseline level), will be permitted to pass benchmarking. The operation is however, given a maximum of 12 months to improve their performance in at least one of the indicators to Baseline performance or better. If on the next submission, this is not achieved without substantiated evidence that the situation was beyond the control of the operation (e.g., occurrence of a natural disaster), then the right to use the appropriate Earth Check logo will be withdrawn.

As a standard policy, all Earth Check indicators are continuously reviewed, along with the performance levels which operators have to achieve in order to meet the requirements of the Company Standard. This review takes into account "business-as-usual" changes in practice and equipment, and is used to update, where appropriate, Baseline and Best Practice levels.

These indicators are for guidance only and do not affect the overall benchmarking evaluation.

(Earth Check ${ }^{\circledR}$ is a registered trademark of Earth Check Pty Ltd.)

Table 1. Earth CheckIndicator measure (benchmark) [1].

\begin{tabular}{|c|c|c|}
\hline & Indicator & Content \\
\hline \multirow[t]{2}{*}{1} & Policy & Policy is produced and in place \\
\hline & & Energy Consumption (MJ/Guest Night) \\
\hline \multirow[t]{3}{*}{2} & Energy & Green Power $(\%)^{3}$ \\
\hline & & Greenhouse Gas Emissions (Scope 1 and Scope 2) (t CO \\
\hline & & Potable Water Consumption (kL/Guest Night) \\
\hline \multirow[t]{3}{*}{3} & Water & Water Savings Rating (Points) \\
\hline & & Recycled/Captured Water $(\%)^{3}$ \\
\hline & & Waste Sent to Landfill (m³/Guest Night) \\
\hline \multirow[t]{2}{*}{4} & Waste & Waste Recycling Rating (Points) \\
\hline & & Recycled/Reused/Composted Waste $(\%)^{3}$ \\
\hline \multirow[t]{2}{*}{5} & Community & Community Commitment (\%) \\
\hline & & Community Contributions Rating (Points) \\
\hline 6 & Paper & Paper Products Rating (Points) \\
\hline 7 & Cleaning & Cleaning Products Rating (Points) \\
\hline 8 & Pesticides & Pesticide Products Rating (Points) \\
\hline
\end{tabular}




\subsection{The Study of Tourism Certification}

Certification is defined as a voluntary procedure that assesses audits and gives written assurance that a facility, product, process or service meets specific standards. It awards a marketable logo to those that meet or exceed baseline standards. (Honey and Rome, 2001) So, we see the certification is a way of ensuring that an activity or a product meets certain standards. Within the tourist industry, different organizations have developed certification programs measuring different aspects of tourism: a) quality, for the entire tourist industry, b) sustainability, also for all sectors, and c) ecotourism, for sustainable tourism that takes place in natural, protected, or fragile ecosystems, that may include indigenous communities, and that conforms to the definition above.

Tourism certification programs, such as AAA (Automobile Association of America), have typically measured and compared quality, service, and price, the areas deemed most important to travelers. Today many programs measure, as well, the environmental, economic, social and cultural impacts of tourism businesses. There are three broad categories: Mass Tourism, Sustainable Tourism, and Ecotourism certification programs. They are based on criteria that are either process- or performance-based or a combination of these two, and they may involve first-, second-, or third-party verification or auditing.

Sustainable tourism certification measures a range of environmental, socio-cultural, and economic equity issues both internally (within the business, service, or product) and externally (on the surrounding community and physical environment).

In 2003, the tourism specialist Honey, in one of her report named "Setting Green Standards for the Tourism Industry", she give us the detailed explanation and development of sustainable tourism and Eco-tourism. According to that report, in 2001 it was 59 "green" tourism certification programs in the world. Of these, the majority are for accommodations (68 percent), but there are a growing number of certification programs covering other sector of the tourism industry, including spots facilities, destinations, transport, tour operations, and naturalist guides. The largest concentration of programs, 78 percent is in Europe, while Latin America has the largest number of new programs in development.

"Most tourism certification programs are operated by governments in developed countries and by NGOs in developing countries (Font and Sallows, 2002). The large majority of certification programs are in Europe while there are only a handful in Africa, Asia-Pacific, Caribbean and the Americas. Most of these programs target accommodation facilities and do not include socio-cultural or economic criteria (WTO, 2002). A few programs like STEP and Green Globe 21 are global programs, whereas the rest certify on a regional, national, or local level.”

\subsubsection{Common Components of Certification Programs}

According to Honey, she said certification programs within the travel and tourism industry vary widely and they do all have several common features, which includes:

1) Voluntary Enrollment

At present, all "green "certification programs in the travel and tourism industry are strictly voluntary. But there are also some governments do require hotels to be certified under the five-star rating system to have a license to operate.

2) Standards and Criteria

Certifications require that businesses be assessed by measuring their level of compliance with prescribed criteria and standards. This can be done by using one of two broad methods: a process that sets up an environmental management system tailored to the business, or a performance that measures every business against a common set of environmental and socioeconomic criteria or benchmarks.

3) Assessment and Auditing

All certification programs award logos based on some kind of assessment. Assessment or auditing can be first-, second-, or third-party, that is, it can be done by the business itself, by an industry trade association, or by an independent firm, NGO, or even the government. There are an estimated 200 certifying agencies around the world, most of which are for-profit companies. Some are accredited, that is they are recognized by a national accreditation body; others are not.

4) Logo

All programs award use of a selective logo, seal, or brand designed to differentiate their product in the marketplace and to be recognizable to consumers. Most permit the logo to be used only after certification is achieved. Green Globe 21, however, allows businesses or destinations that become members to use its logo from the time they officially commit to becoming certified, and before they have implemented any actions and been 
externally audited. Once certified, a slightly different logo—one with a check in the middle—is issued. A number of experts say such a slight distinction is lost on most consumers. Many certification programs give logos for different levels of achievements- one to five suns, stars, or leaves, for instance. This is considered superior to a single logo because it encourages business to improve and helps customers to distinguish among certified products.

5) Membership and Fees

Many certification programs are initially financed by governments, aid agencies, or NGOs, but for the longrun aim is to make them self-supporting, they charge an enrollment fee to businesses seeking certification. This money is used to run the program and to support advertising and promotion of the logo and of the companies that are certified. The certification programs, and/or auditing bodies, also charge fees for the assessments they provide and for auditing services, usually structured according to the size and income of the company.

\subsubsection{Methodology: Process vs. Performance}

Broadly stated, tourism certification programs can be divided into two methodologies: 1) process-based using environmental management systems, or 2) performance-based using environmental and usually socio-cultural and economic criteria, standards, or benchmarks.

Process-based certification programs: The process-based certification programs are all variations of environmental management systems (EMS). The EMS method has become a popular tool in helping management conduct baseline studies, put together a program plan, do staff training, and set up systems for on-going monitoring and attainment of set environmental targets such as pollution, water, and electricity reduction. Currently, EMS is being widely used within the tourism and travel industry. The best known EMS standard for "green" hotel certification is the ISO14001, developed in the wake of the 1992 Rio Earth Summit as one of several industry responses to the increasing public interest in sustainable development. ISO14001 contains an EMS standard against which a business, regardless of its size, product, service, or sector, is certified. It can be used by tourism companies or any other type of business and can be applied corporate-wide, at a particular site, or to one particular part of a firm's operations. The exact scope of ISO14001 is up to the discretion of the company. An ISO14000 environmental management system includes five elements [3]:

- An environmental policy

- An assessment of environmental aspects and legal and voluntary obligations

- A management system

- A series of periodic internal audits and reports to top management

- A public declaration that ISO14001 is being implemented

Performance-based certification programs: Performance-based programs use a set of externally-determined environmental and usually socio-cultural and economic criteria or benchmarks to measure all companies seeking certification. Today, an increasing number of programs are performance-based, or are a combination of both process and performance methodologies. Performance-based systems are used mainly by national or sub-national certification programs to compare and judge businesses against a set of common criteria. In most cases, an independent auditor is contracted to inspect products and services to ensure that the criteria are met. If so, the business or product is awarded a logo that may have several different levels in order to indicate current status and to encourage improvement in fulfilling more or higher criteria. Programs that are the largely performancebased certification programs, they are less costly and permit companions among business. These programs can be scaled according to size and complexity of the product or company, and can therefore be more easily applied and managed by small and medium sized enterprises.

Increasingly, however, many of the newer or revamped programs represent a hybrid of process (management systems) and performance (standards or benchmarks).

\subsubsection{Types of Certification Programs: Mass Tourism, Sustainable \& Ecotourism}

While this process-performance distinction is extremely important, certification programs can be categorized with a wider lens than methodology. In terms of developing public policy, model programs, international standards, and accreditation systems, it is helpful to define three fundamental types of certification: conventional (sometimes called mass) tourism, sustainable tourism and ecotourism certification.

- Conventional tourism certification:

These are certification programs that cover companies within the mass market or conventional tourism industry. 
They are based on setting up environmental management systems (often ISO14001 or their derivatives) tailored to the individual business and out-lining the steps to be taken to achieve certification and a logo. For hotels, for instance, such programs monitor compliance with existing legislation, set targets for improvement, and highlight "best practices" which go beyond compliance. They involve an emphasis on adopting environmentally- friendly, usually cost-saving procedures and renovations. Often these mass certification programs are developed and financed by the industry trade associations who are the main stakeholders involved in design and implementation. Some allow certification at a corporate level (a hotel chain or tour operator) or whole destination (Green Globe 21), rather than at each site-specific individual unit. Mass tourism certification programs can lead to some "green" innovations, but they are insufficient to generate sustainable tourism.

- Sustainable tourism certification:

Sustainable tourism certification measures a range of environmental, socio-cultural, and economic equity issues both internally (within the business, service, or product) and externally (on the surrounding community and physical environment) [4]. It uses primarily a performance-based system, third-party auditors, and a multifaceted questionnaire drawn up in consultation with a variety of stakeholders. It may also include creating or implementing a management system to help establish better and more efficient environmental procedures within the business. Most often sustainable tourism certification (such as ECOTEL) involves individual or site-specific businesses, such as hotels and lodges.

- Ecotourism certification

This covers those businesses that describe themselves (through their brochures, websites, etc.) as involved in ecotourism. These are invariably businesses located in or near natural areas and involved in the protection of pristine and fragile ecosystems. Like sustainable tourism certification, ecotourism certification also focuses on individual or site-specific businesses; its standards are tailored to the conditions of a particular country, state, or region; and it is administered locally. This type of program looks beyond the tourism entity itself to assess how it relates to and benefits the local community and the ecosystem in which it operates. The criteria measuring how a business impacts its surroundings is not simply an adjunct; it weighs equally with how the business functions internally in terms of its physical plant and staff and guest relations.

From the collected information, we learned that Earth Check announced the opening of an office in Beijing, China on January 16, 2012. Earth Check is trying to build a presence in China and they want to open a market in China. According to PATA (Pacific Asia Travel Association), "by opening an office in Beijing, Earth Check aims to further extend its reach in Greater China and to foster increased understanding of the importance and advantages of adopting sustainable tourism practices that deliver triple bottom line outcomes”.

Through the Earth Check website information and the Pacific Asia Travel Association (PATA) news, we also learned that the Beijing office will be headed by Ms. Yan Key. She is the China Regional Director of Earth Check. We found her contact information on the Earth Check website. We interviewed her and asked her some questions. From Ms. Yan Key, we learned that Earth Check now has about 35 members in China and these are all hotels. Almost all of these hotels are previous Green Globe members, because when EC3 updated Earth Check benchmarking to the Earth Check program, the previous Green Globe members, also EC3 members will use the Earth Check logo. In this paper, our practical investigation and research is on the hotel industry in Sonya, Hainan, China. But in the whole Hainan province, there is not one Earth Check member. Ms. Yan Ke told us Banyan Tree Sanya wanted to apply for an Earth Check assessment and would do so soon.

\section{Methods}

This article pays special attention to combining normative research with empirical research. Normative research provides the theoretical foundation for putting forward questions and describes the Earth Check sustainable tourism certification. Empirical research verifies Earth Check certification and verifies three green hotels through the full and accurate collection of data. This data provides the basis for analyzing and solving questions.

\subsection{Normative Research}

With the rise of ecological tourism in the 1970s and 1980s, sustainable and Eco-tourism certifications were an effective means for distinguishing sustainable tourism from non-sustainable tourism. This attracted global attention.

In particular, normative analysis reflects in the following aspects: 
1) Define sustainable development, sustainable tourism, sustainable and Eco-tourism tourism certification, and other related concepts. This paper also introduces and reviews the definition of sustainable tourism from a scholarly point of view.

2) Introduce the Earth Check certification program and the Earth Check Benchmarking system; both are the basis of Empirical research in three hotels.

\subsection{Empirical Research}

Because of sustainable tourism, the Eco-tourism development in China is still in the initial stages. Data collection is very difficult. Our group has spent a lot of time and energy collecting data. This article uses the empirical research methods which mainly include the following three aspects: The Delphi method, the Field survey, and the Case study method.

1) Delphi method

The authors used questionnaire surveys and interview investigations during this capstone project process. We invited some experts and scholars in sustainable tourism to give us Earth Check certification study advice and help. They helped fill out our questionnaires and replied to our e-mails. We have interviewed: Dr. Dennis Heaton, professor of Management at Maharishi University of Management; Ms. YanKe, Earth Check China's regional director; Fang Luo, the Assistant Manager of the Guesthouse International Hotel Sanya; Mr. Zhong, the CSO (chief sales officer) of the Leaguen Resort Sanya Bay; Mr. Wang, the last Director of Engineering of Boao Golden Coast Hot Spring Hotel; and Wenshan Su, the Marketing Manager of the Haiziyuan International Travel Agency.

2) Field survey

The authors selected the hotel industry in Sanya, China, as an object of research. Meanwhile, we chose three China Green Hotel certified hotels as a sample case study. Through on-the-spot investigation, questionnaire investigation and interviews with hotel staff, we obtained first-hand materials.

3) Case study method

We chose the Guesthouse International Hotel Sanya, the Leaguen Resort Sanya Bay, and the Boao Golden Coast Hot Spring Hotel as our case study examples and we used EarthCheck certification to evaluate these three hotels.

\section{Study Area}

\subsection{The Introduction of Hainan and the Hainan Tourism Industry}

Hainan is a province in the People's Republic of China (PRC). The name "Hainan" also refers to Hainan Island (海南岛, HăinánDăo), the main island of the province. Hainan is located in the South China Sea, separated from Guangdong's Leizhou Peninsula to the north by the shallow and narrow Qiongzhou Strait. The province has an area of 33,920 square kilometers (13,100 sq mi) and is China's southernmost province. By the end of 2010, the population of Hainan was 8,671,518. Hainan has a tropical moist monsoonal climate. Its annual temperature is $23^{\circ} \mathrm{C}$ to $25^{\circ} \mathrm{C}$ and the annual temperature change is less than $15^{\circ} \mathrm{C}\left(27.0^{\circ} \mathrm{F}\right)$. The coldest months are January and February when the temperatures drop to $16^{\circ} \mathrm{C}$ to $21^{\circ} \mathrm{C}\left(61^{\circ} \mathrm{F}\right.$ to $\left.70^{\circ} \mathrm{F}\right)$; the hottest months are July and August, and the temperatures are $25^{\circ} \mathrm{C}$ to $29^{\circ} \mathrm{C}\left(77^{\circ} \mathrm{F}\right.$ to $\left.84^{\circ} \mathrm{F}\right)$. The superior geographic location and particular tropical island climate is the basis of the rapid development of Hainan tourism [5].

In 2000, the numbers of overnight tourists reached 10 million in Hainan, China. Over 20.6 million tourists visited Hainan in 2008, producing total revenues of 19.23 billion Yuan (US \$2.81 billion) from tourism. Of these tourists, 979,300 were from overseas with the largest numbers coming from ROK, Russia and Japan. In 2010, the amount of overnight tourists visiting Hainan was 25.87 million, 663,000 of which came from outside China. Since 2010, the number of overnight tourists has increased 15\% every year. In 2011, there was a record breaking 30 million tourists. Income from tourism was 32.4.billion Yuan (US \$5.10 billion) which was $25.8 \%$ increased from 2010 to 2011.

By the end of 2010, according to the statistical data from the Hainan Tourism department, there were about 300 tourist attractions in Hainan, which included two National AAAAA tourist attractions, eight National AAAA tourist attractions, thirteen National AAA tourist attractions, five National AA tourist attractions and two National A tourist attractions. 
According to the statistical data from the Hainan Tourism department, there were 100 National Star (Star rating system) hotels with 20,000 hotel rooms in Hainan, but by the end of 2011, in only 10 years, this number changed to 306 National star hotel hotels with 67,000 rooms. Sanya has 204 National star hotels and 32,000 hotel rooms. Sanya is the leader in the tourism industry in Hainan province. So, in our empirical research we choose two hotels in Sanya and one hotel in Boao. Boao also belongs to the Big Sanya tourism area. Boao did not have an airport or railway station. Sanya has the biggest Hainan airport, the Sanya Phoenix International Airport and a railway station from the mainland [6].

\subsection{Hotel Introduction}

\subsubsection{Guesthouse International Hotel Sanya}

Guesthouse International Hotel Sanya is the first hotel of the chain, "GUESTHOUSE INTERNATIONAL" brand in China. Guesthouse International Hotel Sanya is located within the Dadonghai sea tourist area, in Hainan Island, China. Customers can stay at a Sanya, Hainan hotel on the mountain-top apex of Sanya City.

The hotel covers an area of 44 mus (about 29333.3 square meters) and the building area covers an area of 13,000 square meters. The mountain forests are $90 \%$ tropical forest. Hotel construction was designed by the United States Hawaii DGH company and the hotel garden was designed by the American SASAKI garden designer company. Hotel construction was according to the international high star standard construction, and was startedon January 8, 2004. The hotel has 228 rooms. The guest room area is large, tonally relaxed has a broad view and is equipped with expensive furniture, cotton fabrics and individualized products. Each room has a balcony so guests can view the sea, and smell the pure and fresh air. All the rooms are equipped with broadband Internet access [7]. The hotel has two guest rooms over the swimming pool. The Hotel's multi-functional hall can hold 200 people and can be used for meetings, banquets and other activities. The food provided is Chinese and Western delicacies. In addition, the hotel has a gym, a billiards room and other recreational facilities. The hotel provides a free sightseeing car for guests, so they can visit the Dadonghai special beach. The hotel location is close to all Sanya City businesses, entertainment spots and tourist destinations. Located close by the hotel is the Sanya People’s Government, the Red Gorge Golf Club, the Xiao Donghai Tourist Zone \& the Hainan Hairun Pearl Science Hall.

The Guesthouse International Hotel Sanya did a lot of work creating a green hotel and they developed sustainable practices in their hotel. In 2009, they were recognized as the Four Silver Leaf Grade "China Green Hotel”.

\subsubsection{Leaguen Resort Sanya Bay}

Leaguen Resort Sanya Bay was constructed by SanyaLeaguen Investment Development Co., LTD, who also built units for the Shenzhen Tsinghua University Institute. Leaguen Resort Sanya Bay was constructed as a National Four-Star standard hotel and they integrated Hainan's first holiday health center, located there with leisure, vacation, rehabilitation, and health programs. Leaguen Resort Sanya Bay is located in the picturesque Sanya Bay, it is 8 kilometers to the downtown area, and is $5 \mathrm{~km}$ from the Phoenix Airport. The Blue Sea is on the south side of the resort and there is a green mountain view on the North side of the resort. Leaguen Resort Sanya Bay was constructed during three periods. During the first phase, construction was according to the national four-star standard. During the second phase 10,000 square meters of holiday apartments were built. The third phase saw the completion of 38,000 square meters of the scale linkage effect [8].

With the resources from Tsinghua University and some famous experts from Beijing, Shanghai and other cities, a 1000 square meter medical buildingand advanced medical rehabilitation center was built. This included physical therapy and diagnosis test equipment. The center provides daily physical examinations, doctors of traditional Chinese Acupuncture, Chinese massage, Chinese medical therapy, health consultations, and scientific and health guidance services. The center also provides the services of top-ranking medical experts. There is also an Entertainment center with complete supporting facilities; a spa, a swimming pool, a gymnasium, a billiards room, a table tennis, chess and card room, reading rooms, an Internet bar, and a beauty salon. The Sea-cycling Healthy Entertainment project provides guests with health consultations, fashion shows, and entertainment. Located in the center of the Sanya Bay Tourism and Resort Area known as the "Long Corridor of Coconut Dream" [9], the hotel boasts an advantageous geographical environment. The hotel is only 8 kilometers away from the urban area of Sanya and 12 kilometers away from the Dadonghai Sea. The hotel faces the Xidao Island Scenic Spot Area which is across the sea to the south and is 18 kilometers away from the TianyaHaijiao Scenic Area to 
the west. The hotel is also 3 kilometers away from the Love World (Thai-style Garden), 40 kilometers away from FushouNanshan and DaxiaoDongtian Scenic Spot Areas, and 3 kilometers away from the Sanya Phoenix International Airport (about a 7 - 8-minute drive).

\subsubsection{Boao Golden Coast Hot Spring Hotel}

From the Boao Golden Coast Hot Spring Hotel website, we find a detailed introduction about this hotel. The Boao Golden Coast Hot Spring Hotel is an "international, intelligent, ecotypic" five-star hotel in BoaoAquapolis, the permanent site of Boao Forum in Asia. It is located at the meeting points of three famous rivers (Wanquan, Jiuqu, Longgun), and it faces the sea. The hotel invites you to embrace the coconut trees, the sandy beach, enjoy thehot springs, and visit the islands as well as the plantations. With its unique environment and advanced sewage system, the Boao Golden Coast Hot Spring Hotel was the first hotel in China which was awarded the prize of "5A Green Hotel” (Five Leaf Grade "China Green Hotel”) [10]. The hotel is located in a very convenient spot, close to the freeway between Boao and Qionghaiand there are shuttles between downtown and the hotel. The Boao Golden Coast Hot Spring Hotel is easy to reach, it's $82 \mathrm{~km}$ away from Haikou Meilan Airport, (this takes only 1 hour by car) and $180 \mathrm{~km}$ away from the Sanya Phoenix Airport, (this takes 2 hours by car).

\section{Data Collection}

In order to evaluate the EarthCheck Certification technology in three hotels in Sanya, China, three methods were used; field investigation, a questionnaire survey and interviews with the hotel managers.

Two kinds of data were collected; the socioeconomic data of Sanya City, and a survey of three representative hotels in Sanya with "green star" ratings. For the field investigation and the questionnaire surveys, we collected data from the following people: EarthCheck China regional director, Ms. YanKe; Assistant Manager of the Guesthouse International Hotel Sanya-Fang Luo; the CSO (chief sales officer) of the Leaguen Resort Sanya Bay; Mr. Zhong, the last Director of Engineering at the Boao Golden Coast Hot Spring Hotel; Mr. Wang, who left the hotel last year, but was Director of Engineering for about 10 years. And some key people like the Marketing Manager of the Haiziyuan International Travel Agency, Wenshan Su.

The secondhand socioeconomic information (Table 2) of the three hotels was collected from official data of related administrative departments, such as the Bureau of Statistics Hotels' Office, the Bureau of Tourism of Hainan, the China EarthCheck website, and the website of the three selected hotels.

The survey data was collected from November 15, 2011 to September 3, 2012. Selection of respondents proceeded according to a two-stage cluster sample. In the first stage, Sanya City was randomly chosen. In the second stage, the three hotels (the Guesthouse International Hotel, the Leaguen Resort Sanya Bay and the Boao Golden Coast Hot Spring Hotel) in Sanya were selected randomly for investigation. Then 50 in-depth interviews and 400 questionnaires were completed according to the investigation plan for Hainan. First, we conducted about two-hour, face to face interviews with hotel leaders and the EarthCheck China hotel-leader. Questions were designed for open answers. Owing to the relatively open structure of the interviews, new issues of particular interest to the respondents could arise according to a semi-structured methodology (Board and Zhao, 2002; Stringer et al., 2007). Through these interviews, information on the standard usage of the Earth Check technology was collected.

\section{Result}

\subsection{Benchmark Review}

Per standard policy, all EarthCheck indicators are reviewed annually, along with the performance levels which operators have to achieve in order to meet the benchmarking requirements. This review takes into account "business-as-usual" changes in practices and equipment, and is used to update, where appropriate, Baseline and Best Practice levels. The assessments (Table 3(a)-(c)) we undertook were 2011 Earth Check indicators.

Table 2. The activity measures of the three hotels in Sonya in 2011.

\begin{tabular}{cccc}
\hline Activity Measures & Guesthouse International Hotel Sanya & Leaguen Resort Sanya Bay & Boao Golden Coast Hot Spring Hotel \\
\hline Rooms & 228 & 428 & 336 \\
Guest Nights (gn) & 107,453 & 237,454 & 152,073 \\
Occupancy Rate (\%) & 64.56 & 76.00 & 62.00 \\
Area Under Roof $\left(\mathrm{m}^{2}\right)$ & 13,000 & 30,000 & 35,000 \\
\hline
\end{tabular}




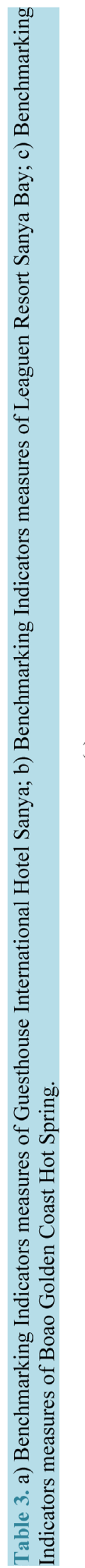

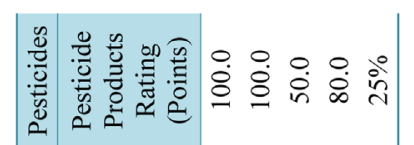

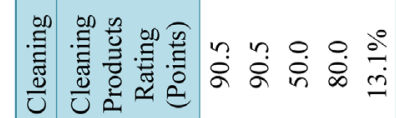

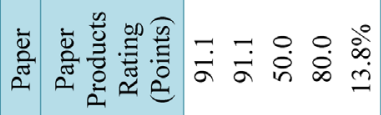

3.

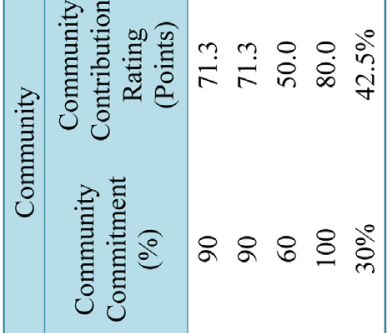

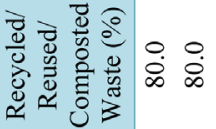

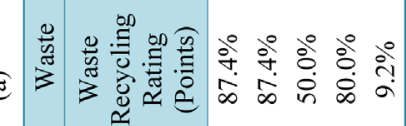

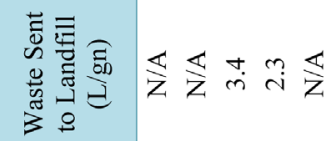

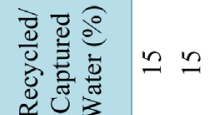

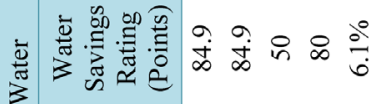

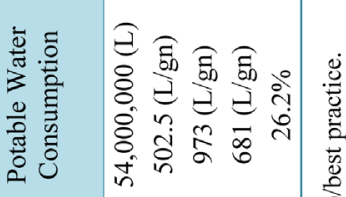

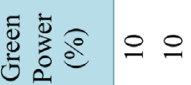

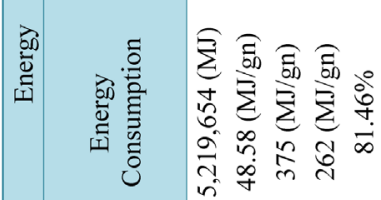

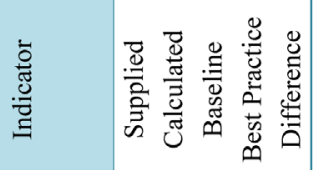

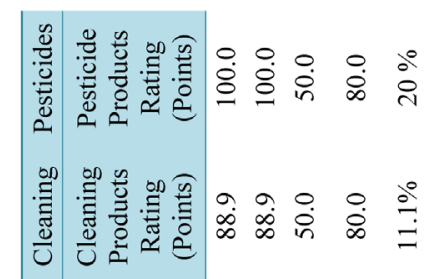

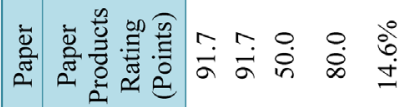

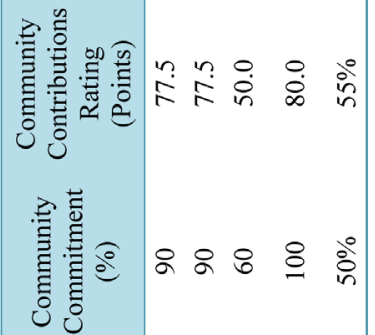

चें चुे

थ

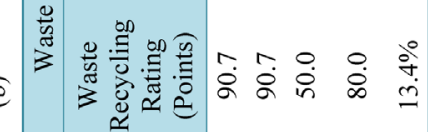

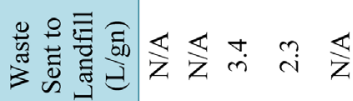

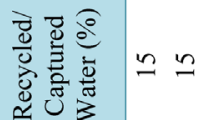

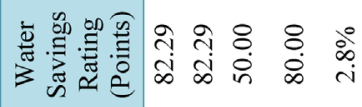

索

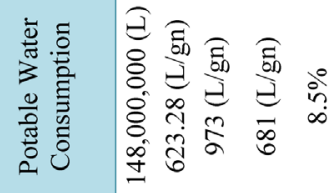

ฮัँ

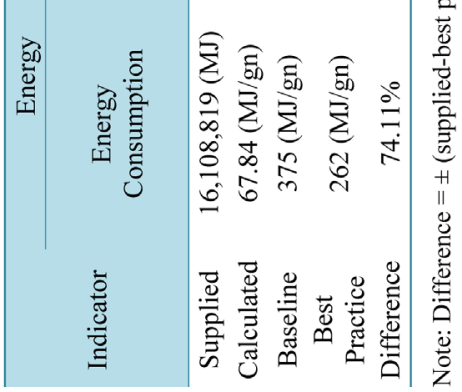

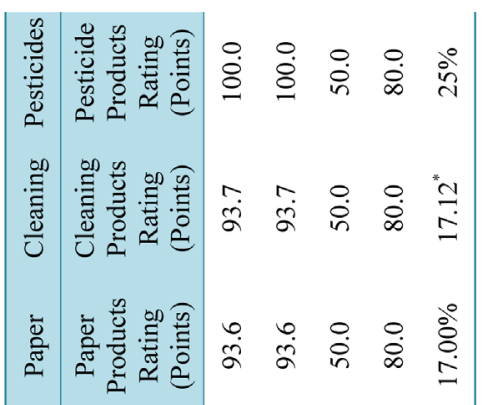

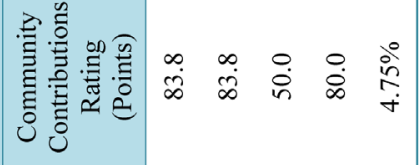

苛

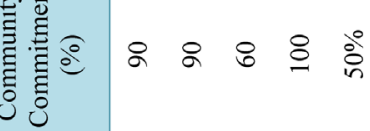

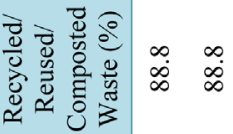

ê

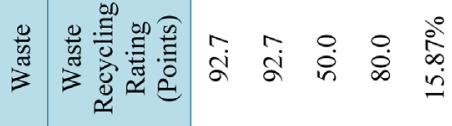

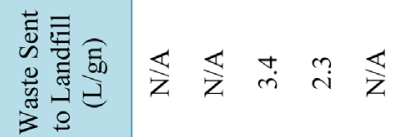

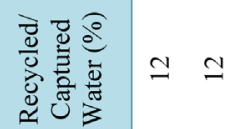

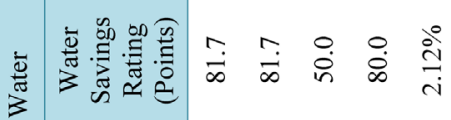

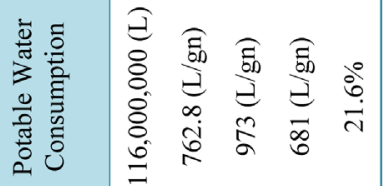

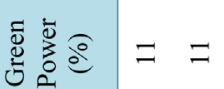

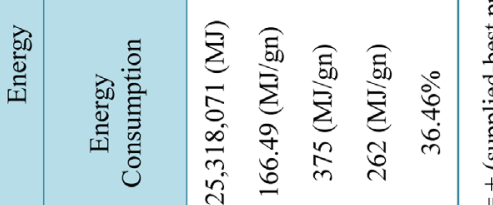

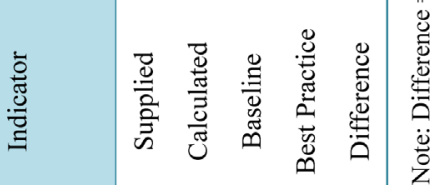

December 2014 | Volume 1 | e854 
To meet the requirements stipulated in the Earth Check Company Standard, the benchmarks for all the submitted Earth Check indicators need to be at, or better than, the Baseline level. Baseline and Best Practice performance levels are set with reference to the type of activity (registered sector/s) and appropriate national and international data which take into account social, geographical and climatic impacts.

First-time benchmarking operations that fail to meet the minimum requirements (Baseline performance or better) for up to two submitted Earth Check indicators (with a third indicator within $10 \%$ of the Baseline level), will be permitted to pass benchmarking. The operation is however, given a maximum of 12 months to improve performance in at least one of the indicators to Baseline performance or better. If on the next submission this is not achieved without substantiated evidence that the situation was beyond the control of the operation (e.g., occurrence of a natural disaster), then the right to use the appropriate Earth Check logo will be withdrawn.

As a standard policy, all Earth Check indicators are continuously reviewed, along with the performance levels which operators have to achieve in order to meet the requirements of the Company Standard. This review takes into account "business-as-usual" changes in practices and equipment, and is used to update where appropriate Baseline and Best Practice levels.

\subsection{Analysis of the Three Hotel Case Studies Results}

All three hotels use sustainable tourism development practices. According to the results of our investigation and assessment (Tables 3(a)-(c)), all three hotels in China, which are the Guesthouse International Hotel Sanya, GuestHouse International Hotel Sanya and Leaguen Resort SanyaBay, have passed the requirements and are recognized as an Earth Check Benchmarked Accommodation-Vacation Hotel. Nine of the ten assessed Earth Check indicators are at or above the Baseline level.

Energy Consumption (MJ/Guest Night) for the year 2011 (1 January 2011-31 December 2011) of the three hotels were separately 48.58 MJ/GN, 67.84 MJ/GN, $166.49 \mathrm{MJ} / \mathrm{GN}$, which was respectively $81.14 \%$, 74.1\%, $36.47 \%$ better than the Best Practice level and above the Bas-eline level (Figure 1).

Green Power (\%) for the year 2011 (1 January 2011-31 December 2011) of the three, hotels was separately $10 \%, 11 \%$, and $12 \%$, which are important actions for earth check. The indicator is for guidance only and do not affect the overall benchmarking evaluation (Figure 2).

As Tables 3(a)-(c) show, the remaining of seven indicators in the three hotels are at or above the Best Practice level. So, based on our assessment, the Guesthouse International Hotel Sanya, Leaguen Resort Sanya Bay and Boao Golden Coast Hot Spring Hotel could win the Earth Check Bronze Certification award (also called Bronze Benchmarked).

\section{Conclusions}

These three hotels-the Guesthouse International Hotel Sanya, the Leaguen Resort Sanya Bay and the Boao Golden Coast Hot Spring Hotel could win the Earth Check Bronze Certification award. If they plan to register to

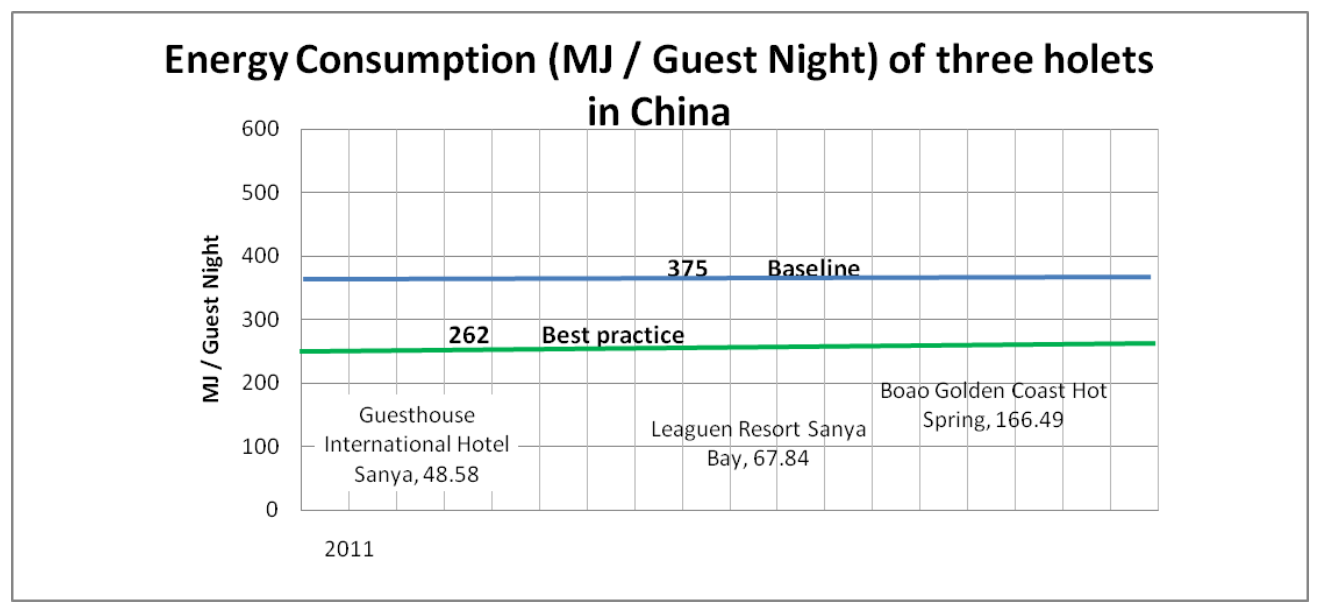

Figure 1. Energy consumption. 


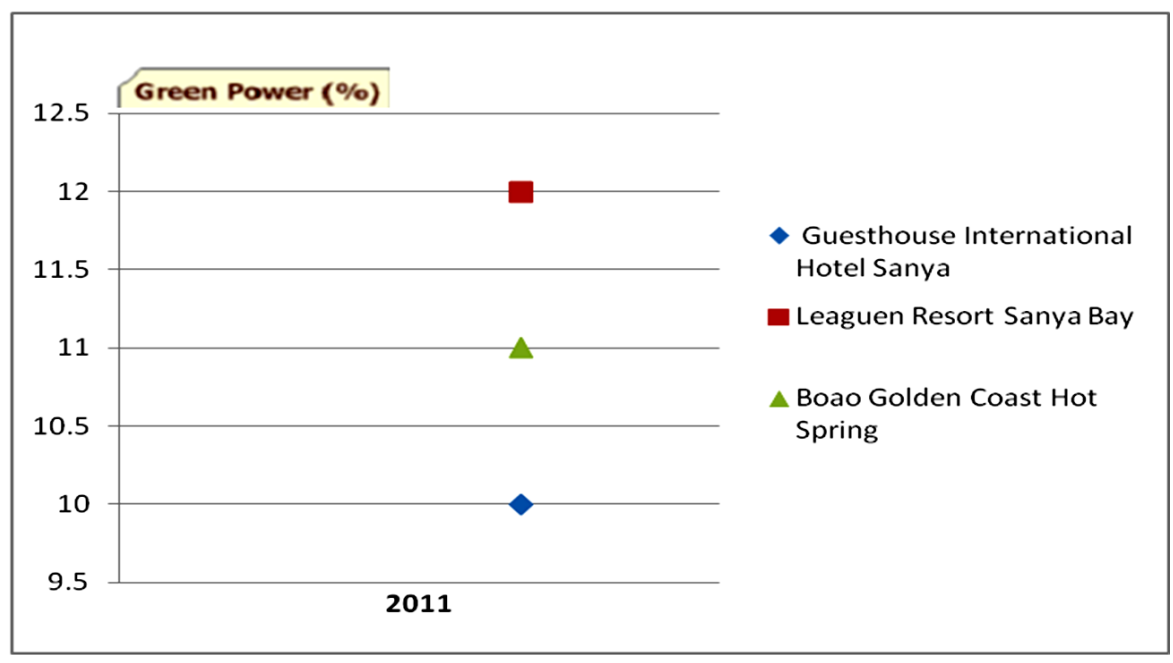

Figure 2. Green power.

be assessed by Earth Check and pay Au \$450 (ex.GST) (Au \$450 is equal to US \$463.95), they will receive the Bronze Benchmarked Logo, a Benchmarking Assessment report, a Benchmarked Certificate and additional marketing collateral to promote their achievement. In order to do better in sustainable tourism development, these three hotels could register to be certified by Earth Check. Earth Check will provide certification services and develop sustainable policies for these hotels. In the future they will receive the Silver, Gold, or Platinum Certified Logo, a Certification Assessment report, a Certified Certificate and additional marketing collateral to promote their achievement. These hotels could do very well in sustainable development with Earth Check's help.

These hotels passed the requirements of the Earth Check Benchmarked Accommodation-Vacation Hotel, which does not mean they should stop working on developing their sustainable practices. The Earth Check Bronze Certification (Benchmarked) is like a key for hotels that opens a big door in developing their sustainable tourism. This is why Earth Check benchmarking indicators are reviewed every year and they update their appropriate Baseline and Best Practice levels. Improvements in all of the Earth Check indicators will not only help the environment, but can also help reduce operational costs. So, a company in the tourism and travel industry should continue to meet the new benchmarking requirements of the Earth Check program.

\section{References}

[1] Poser, E.A. (2009) Setting Standards for Sustainable Tourism: An Analysis of US Tourism Certification Programs. Master's Projects, The Nicholas School of the Environment of Duke University, Durham.

[2] Who Is Earth Check? (2012). http://www.statscrop.com/www/earthcheck.org

[3] Scott, J.A., Buckingham, T. and Watt, M. (2004) Travel and Tourism Industry Benchmarking Methodologies. Cooperative Research Centre for Sustainable Tourism Research Report Series, Gold Coast.

[4] Han, J.-H. and Mills, J.E. (2006) Zero Acquaintance Benchmarking at Travel Destination Websites: What Is the First Impression That National Tourism Organizations Try to Make? International Journal of Tourism Research, 8, 405-483. http://dx.doi.org/10.1002/jtr.581

[5] Keeping Track of Our Changing Environment from Rio to Rio+20 (1992-2012), UNEP.

[6] Wikipedia (2012) Tourism in China. http://en.wikipedia.org/wiki/Tourism_in_China

[7] Earth Check Builds Presence in China. (2012). http://cn.earthcheck.org/

[8] Earth Check Opens Office in Beijing. (2012). http://www.earthcheck.org/news/earthcheck-opens-office-in-beijing,-china.aspx

[9] There Are Five Tourist Attraction Rating Categories of China: A (or 1A, the Lowest Level), AA (2A), AAA (3A), AAAA (4A) and AAAAA (5A, the Highest Level), 2011. (2011) Government Annual Report of Hainan Province, 2, 34-83.

[10] Welcome to the Guesthouse International Hotel Sanya. (2012) http://www.guesthouseintl.com/hotels/hainan 